\title{
Psycholinguistic Approach to the Foreign Language Competence Formation of Future Seafarers
}

\author{
Olena Tyron \\ Kyiv State Maritime Academy, Kyiv, Ukraine \\ Email: ollena22@hotmail.com
}

How to cite this paper: Tyron, O. (2017). Psycholinguistic Approach to the Foreign Language Competence Formation of $\mathrm{Fu}$ ture Seafarers. Psychology, 8, 663-675. https://doi.org/10.4236/psych.2017.84043

Received: January 23, 2017

Accepted: March 28, 2017

Published: March 31, 2017

Copyright $\odot 2017$ by author and Scientific Research Publishing Inc. This work is licensed under the Creative Commons Attribution International License (CC BY 4.0).

http://creativecommons.org/licenses/by/4.0/

\begin{abstract}
This article describes the study of psycholinguistic process of speech perception by future seafarers. The described study proves the role of psycholinguistic aspects in the process of forming foreign language competence of seafarers. Diagnostics of the level of perceptual skill development has been carried out and the way of its further correction in the process of English language teaching at higher educational institutions for maritime training areas have been worked out. Requirements for psycho-acoustic properties of the voices of the future seafarers are caused by the conditions of their life activity at sea and their future professional duties. Noise, vibration, bad weather require skills to wield the power of voice (psycho-acoustic dimensions). The need to speak in such conditions requires the ability to control the volume of voice when speaking. Based on the fact that the students of higher educational institutions of marine areas-the future officers, their speech should be clear and assertive. Psycho-acoustical aspect, in our opinion, precedes the development of speech perception skills and the ability to control the sound of speech. The results of diagnostics of the formed level of seafarers' skills to assess the quality of their speech and their formed level of skills and abilities as a listener have prompted us to develop psycholinguistic exercises to improve speech perceptual skills of future seafarers that will enable them to improve professional communication and interpersonal communication at sea.
\end{abstract}

\section{Keywords}

Foreign Language Competence, Psycholinguistic Approach, Perceptual Skills, Speech Activity of Seafarers, Psychological Techniques for Speaking Skills Correction 


\section{Introduction}

Language activity is the main and universal means of communication between people in society and at the same time-the main means of communication, which makes the scope of psycholinguistics quite diverse. Modern psycholinguistics studies many situations considering the interaction of communicants, explores how people influence each other in the communication process to achieve fulfillment of desire, which is directly or indirectly expressed. Modern psycholinguists develop advanced domestic and global approaches to the speech and language research, offering the latest views on the communication phenomena, phenomenon of ontogenesis of language, speech and thinking of a person (Cole \& Scott, 1974; Cleason \& Ratner, 1998, etc.), speech perception phenomena (MacKay, 1987), speech and activity (Leontiev, 1974). They present the latest results of theoretical and experimental psycholinguistic research connected with speech perception. The scientists clearly distinguish two sides of speech perception-a motor side (Studdert-Kennedy, 1974; Liberman \& Mattingly, 1985 etc.) and an acoustic side (Liberman 1965; Zimniaya, 1991; Ventsov \& Kasevich, 2003 etc.).

Being at the crossroads of linguistics and psychology, psycholinguistics actively uses the methods of both sciences (Baskakova \& Glukhov, 2009; Miller \& Iard, 1963; Zasekina \& Zasekin, 2002). Thus, in the analysis of specific linguistic facts, psycholinguistics draws extensively descriptive and comparative descriptive approach.

One of the branches of psycholinguistics is phonosemantics that studies the emotional content of speech sounds, exploring ratio in linguistic consciousness of sound and meaning. In terms of sound symbolism, sound is in unity with the opinion of the speaker as well as the one who listens to (the recipient). According to most scientists, the sound itself does not carry any meaning. This means that the sound image of the words is conditional. Other researchers experimentally prove that sound is motivated and has a certain meaning.

The process of formation of foreign language competence of the future seafarers is studied by educational and linguistic sciences. Psycholinguistics can take its place in this process, if not the key but necessary, the role of which should be considered. One of the factors in the successful formation of foreign language competence of a seafarer is psycholinguistic perception of speaking. Our research shows the relevance of this little-studied side of foreign language competence of seafarers. This is associated with ergonomic features of the work of seafarers, such as: noise, vibrations, weather conditions, etc.

\section{Experimental Materials and Methods}

We present here an empirical research which has been carried out at the Kyiv State Maritime Academy (Ukraine). On the basis of theoretical positions, we have developed a methodology and identified methods of experimental psycholinguistic research. Methods are given in Table 1. The studies have been conducted at the Faculty of Navigation of the Kyiv State Maritime Academy in 2015. Within two years180 students have been involved in the study (diagnostics). 
Table 1. Research methods of studying the psycholinguistic aspects of foreign language competence of future seafarers.

\begin{tabular}{lll}
\hline \multicolumn{2}{c}{ Method } & \multicolumn{1}{c}{ Purpose of the Methods } \\
\hline 1 & $\begin{array}{c}\text { The individual speech profile } \\
\text { of the auditor (listener); }\end{array}$ & $\begin{array}{l}\text { - determine the level of development of perceptual skills } \\
\text { (perception of speaking); }\end{array}$ \\
& $\begin{array}{l}\text { Semantic personal } \\
\text { speech profile. }\end{array}$ & $\begin{array}{l}\text { - determine the ability to analyze and control sounding } \\
\text { of voices; } \\
\text { analyze the qualitative characteristics of speaking. }\end{array}$ \\
\hline
\end{tabular}

\section{Theory}

Theoretical basis of our research stands includes three concepts:

-Theory of speech production;

-Theory of speech perception;

-Theory of speech reflection.

Psycholinguistic theory of speech production developed by representatives of the Moscow Psychological and Linguistic school became the theoretical basis of the study of psycholinguistic aspects of the formation of foreign language competence of future seafarers. The origins of their views relate to the works of L. Vygotsky (1982), the concept of activity launched in 1950-1970-ies by Leontiev (1974) and preceded by the works of Luria (1975) and Zhinkin (1958).

For disclosure of psycholinguistic aspect we also referred to the reflective psycholinguistics. Most psycholinguistic methods, starting with the semantic differential by Osgood (1967) have a reflective character. They are associated with certain judgments of the surveyed on their speech or language.

In modern psychology, the most common feature is the distinguishing of three levels of speech perception: sensory, perceptual and semantic. The first level, as a rule, is related in linguistics to the sound level (sound insulated), the second - to the word (isolated words), and the third-to the text (Leontiev, 1999; Tarnopolskyi, 2006; Zimniaya, 1991; Cole \& Scott, 1974 etc.).

In accordance with the ideas of Zimniaya (1991) and Rubinstein S. (1976), understanding is a necessary level of speech perception. The basis of the theory of acoustic listening is the position of the gradation of perception of the flow of speech by the recipient, followed by the identification of the circuit elements. Syllable is considered to be the minimum unit of perception of speech (Zasekina L., Zasekin S.). Meanwhile I. Zimniaya (1985) developed a phase of sensory-perceptual processing of the speech signal.

On the sensory level there are following phases:

- expansion of the acoustic and the transition to the code of nerve impulses;

- distinguishing and retention in the memory temporary signs necessary for a decision about the statement.

On the perceptual level these phases are:

- primary speech synthesis based on the recognition operations;

- complete synthesis of speech, acquisition of categorical identification and individual attributes; 
- phrasal synthesis of words in the message;

- secondary analytic-synthetic processing of words to determine the meaning;

- understanding the thought and content after a certain substitute;

- transition to natural internal code.

Ukrainian scientist Tarnopolskyi (2006) notices that this understanding translates phrasal speech into text. The author distinguishes the following phases of the hearing as a speech activity (Tarnopolskyi, 2006: pp. 127-130):

- motivation and incentive;

- orienting-investigative (internal reproduction of another's speech);

On the basis of the forecast the matrix of the statement is being created in the process of inner speech, the meaning of the phrase is being integrated and then the whole message is being integrated.

- phase of executive action (outcome).

A. Ventsov and V. Kasevich (Ventsov \& Kasevich, 2003: pp. 55-56) noted that while reflecting the actual process of speech perception we must take into account the stage when there is only one source of information in the disposal of the listener, an acoustic signal. The perceptual mechanisms include a module that works directly with the information that corresponds to the psychoacoustic module. The scientists note that speech perception is preceded by psychoacoustic module.

Speaking about the role of psycholinguistics as a science in the process of training of the future specialists, Kalmykova (2005), Ukrainian psychologist, notes that "neglect of psycholinguistics as a practical tool that helps to see and understand the internal mechanism of perception of information by an individual, as well as self-regulate this mechanism on the enough evidence-based the level, causes eventually less qualitative preparedness of any specialist to practice".

Thus, we accept that:

- acoustic characteristics of the voice perception have psycholinguistic aspect and can be studied empirically;

- formation of foreign language competence includes the understanding of internal mechanism of perception of information by an individual.

\section{Results}

The subject of the study is the foreign language competence.

Individual profile of an auditor (listener) is the method of the determining the level of the development of perceptive skills and abilities of surveyed (in our research of future seafarers). The students were proposed to make up the individual graph profile of the auditor (listener). Then we were comparing these graphs with the ideal graph. This made it possible to determine the state of formation of perceptual skills of the auditors, determine which properties need to be improved or corrected. Bellow you see the example of the ideal graph (see Figure 1).

Interpretation of the results is carried out according to the recommendations (Baskakova \& Glukhov, 2009: p. 72). 


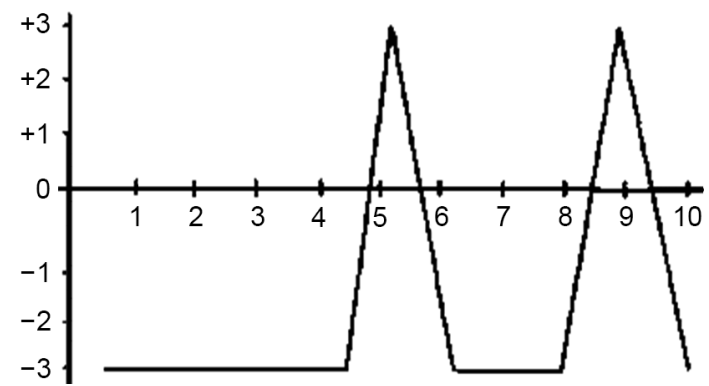

Figure 1. Ideal profile of the auditor (listener).

Totally, 180 graphs were made up, but for the further interpretation of the auditors' speech we selected 140 profiles created by full-time students, as we consider the correspondence department students not to be the future but already formed seafarers.

Questions that can be used to assess attention and commitment in the speech perception:

1) Is it easy to get distracted while I am listening?

2) Do I have to pretend that I am listening to?

3) Do I listen only to be polite?

4) When the other person talks slowly, do I begin to dream?

5) Do I have to listen when tired of listening?

To the first question $86.4 \%$ of the surveyed responded-"sometimes it happens". The result is completely opposite to the model of an ideal profile.

To the second question $76.8 \%$ of the surveyed responded-"quite peculiar to me". The result is opposite to the model of the ideal profile.

To the third question $81.6 \%$ of the surveyed responded-"never" and $10 \%-$ "usually does not happen". The result corresponds to the model of an ideal profile.

To the fourth question $73.6 \%$ of the surveyed responded - "usually does not happen". Results are approaching the ideal model profile.

To the fifth question answers were distributed equally: half of the students said-"enough peculiar to me" (the result is approximate to the ideal profile) and half of the students said- "usually does not happen" (the result is completely opposite to the model of the ideal profile). Thus, there is need to improve students' attention and focus of speech perception while speaking and listening. Particular attention should be paid to the development of concentration during the listening.

Questions reflecting such auditors' qualities as: lack of restraint and the desire to display own "ego":

6) Do I often interrupt the interlocutor?

7) Possibly, I do not listen but I am thinking of the answer?

8) Don't I make hasty conclusions?

To the sixth question $89.6 \%$ of the surveyed responded-"not usually" or "almost never". The result is close to the ideal profile.

To the seventh question $89.6 \%$ of the surveyed responded-"sometimes it 
happens" or "do not know".

To the eighth question $68.8 \%$ of the surveyed responded-"sometimes it happens" (the result is opposite to the model of the ideal profile), $21.6 \%$ - "not usual" and 9.6\%—“do not know".

Availability of sufficient proportion of the responses "do not know" to this question block indicates that students have not thought of how much they display their "ego" in communication.

Questions which evaluate memory properties:

9) Do I try to keep in mind the basic facts?

The majority of the surveyed (89.6\%) responded-"peculiar to me". The result corresponds to the model of an ideal profile.

The question related to the auditor's emotional stability (the ability to separate the personal predilections and objective perception):

10) Do I take a negative position to the speaker?

To this question $76.8 \%$ of the studied said- "never". The result corresponds to the model of an ideal profile. The small number of the surveyed (23.2\%) responded-"sometimes it happens" that is not critical with respect to the ideal profile.

The result of the study of "Individual profile of an auditor" (proximity to ideal profile):

- high level of proximity-0\%;

- middle level of proximity-37\%;

- low level of proximity-63\%.

With the help of the method "Individual profile of an auditor" the following drawbacks in the perception formation as a determinant of communication skills of the future seafarers have been found:

- lack of attention and concernment in the perception of speech;

- lack of concentration during the hearing;

- the students have not thought of how they display their "ego" in communication.

The results show that the developments of skills connected with these drawbacks require improvement in the process of seafarers training.

\section{Methods of Assessing the Quality Characteristics of Speech by Means of Semantic Differential Method}

Successful communication of students on the ship (during their shipboard training) depends not only on what is said but how it is said. Therefore, we have made the speech of the student profile and evaluated the properties of speech of students, using semantic differential method. This method was suggested by an American psychologist Ch. Osgood, who developed a way to control the "music of words" and called his method "semantic differential". Thanks to his method it has been proven that certain sounds affect the mental state of a man, and thus this effect could be measured. The method was tested in 70 years, conducted in various academic institutes and laboratories for over 15 years and continues to 
this day. Our task is to determine which properties of speech are the most important for students-future seafarers and what is the magnitude of differences between experts, self-assessment and desired quality of the statements. Differences (quantitative) between personal and expert evaluation of more than one point treated as inadequate self-esteem. Testing was conducted in four phases:

1) Preparation of the semantic personal speech profile.

2) Determination of the perfect speech.

3) Drawing up of the expert profile (profile up or a teacher, or someone from friends).

4) Interpretation of results.

At this stage of the empirical research the students were asked to estimate general impression of their voice while speaking and to express their desired quality of voice (give points). We used the scale of 7 points from minus 3 to plus 3 zero included. Then the experts (teachers with the group of students) gave an expert mark of the voice quality of every student. Thus each surveyed got an answer sheet with three marks in each index. The language teacher may give personal recommendations to each student having interpreted these sheets. Anyway, we are researching this aspect of foreign language competence with didactic purpose. To make the teaching of future seafarers more effective, we were interested in general tendencies. Therefore, we calculated average index on all positions. Using the median value it was possible to determine the central tendency of the group studied. The results of this stage you can see in Table 2.

As can be seen from the Table 2, the difference between the personal (subjective) and expert (objective) estimates is no more than one point. Thus, the subjective evaluation of speech quality of the surveyed can be considered adequate. The difference between the personal (subjective) and the desired estimates is more than one point on positions: active, loud, expressive, emotional-indicates that students are aware of the need to develop clear, assertive, loud speaking as a tool for communication and dialogue in the conditions of life at sea.

Table 2. The results of the defined central tendency in the assessment of speaking according to the list of subjective scales.

\begin{tabular}{cccc}
\hline $\begin{array}{c}\text { Psycho-acoustic } \\
\text { qualities of the voice }\end{array}$ & $\begin{array}{c}\text { Personal mark } \\
\mathrm{M}_{\mathrm{e}}\end{array}$ & $\begin{array}{c}\text { Expert mark } \\
\mathrm{M}_{\mathrm{e}}\end{array}$ & $\begin{array}{c}\text { Desired mark by } \\
\text { the surveyed } \mathrm{M}_{\mathrm{e}}\end{array}$ \\
\hline Beautiful & 3 & 2 & 2 \\
Pleasant & 3 & 2 & 3 \\
Nice & 2 & 2 & 1 \\
Calming & 1 & 1 & 1 \\
Natural & 3 & 2 & 3 \\
Vivid & 3 & 2 & 2 \\
Quick & 3 & 2 & 2 \\
Active & 1 & 2 & 3 \\
Loud & 1 & 1 & 3 \\
Expressive & 1 & 1 & 3 \\
Emotional & 1 & 1 & 3 \\
\hline
\end{tabular}


Table 3. The results of the defined central tendency in the assessment of speaking according to the factor of quality.

\begin{tabular}{cccc}
\hline $\begin{array}{c}\text { Psycho-acoustic } \\
\text { qualities of the voice }\end{array}$ & $\begin{array}{c}\text { Personal mark } \\
\mathrm{M}_{\mathrm{e}}\end{array}$ & $\begin{array}{c}\text { Expert mark } \\
\mathrm{M}_{\mathrm{e}}\end{array}$ & $\begin{array}{c}\text { Desired mark by } \\
\text { the surveyed } \mathrm{M}_{\mathrm{e}}\end{array}$ \\
\hline Disgusting & -3 & -3 & -3 \\
Nasty & -3 & -3 & -3 \\
Bad & -2 & -3 & -3 \\
Annoying & -3 & -2 & -3 \\
Campy & 0 & 1 & -3 \\
\hline
\end{tabular}

For the further research we analyzed the students' speaking taking for the criteria the factor of quality. The students were asked to estimate their own voice. Then we used the same procedure (got a desired and an expert marks). The results of this stage and indexes you can find in Table 3.

The difference between the personal (subjective) and expert (objective) estimates is no more than one point. Thus, the subjective assessment of the quality of speaking is considered to be adequate. The difference between the personal (subjective) and the desired estimates exceed one point on the position of "campy". This indicates that students feel the naturalness of speech to be more appropriate.

The analyses of the speech activity may be a simple statement of the fact because we cannot change such properties of sounding as tempo, rhythm etc. The results of the analyses of students speech using the criteria of the factor of activity is given in the Table 4.

The difference between the personal (subjective) and expert (objective) estimates is no more than one point that gives grounds to consider subjective assessment of speech activity of students to be adequate.

While analyzing the sounding of the speech using the criteria of emotional expressiveness we were more interested in the surveyed ability to change the sounding of the speech from quiet to loud. The results of this part of analyses (Table 5) made the students think of correcting and improving their abilities to desired results.

The desired rating of the emotional expression of the speech of most students differs from the subjective and objective assessments by more than one point which indicates the inadequacy of subjective assessment of emotional expression and the need for further correction.

The most difficult part of the analyses for the surveyed was the estimation of the acoustic qualities of their voice using the criteria of intelligence. Most of the surveyed answered that it depended on circumstances, not always the same. At least, it made the students think of such qualities of their speech sounding as vulgarity, seriousness and cleverness. The results are given in Table 6 and show that the desired rating according to the factor of intelligence differs from the subjective and objective marks more than one point, therefore the speech of surveyed needs further correction. 
Table 4. The results of the defined central tendency in the assessment of speaking according to the factor of activity.

\begin{tabular}{cccc}
\hline $\begin{array}{c}\text { Psycho-acoustic } \\
\text { qualities of the voice }\end{array}$ & $\begin{array}{c}\text { Personal mark } \\
M_{e}\end{array}$ & $\begin{array}{c}\text { Expert mark } \\
M_{e}\end{array}$ & $\begin{array}{c}\text { Desired mark by } \\
\text { the surveyed } \mathrm{M}_{\mathrm{e}}\end{array}$ \\
\hline Lifeless & -3 & -3 & -3 \\
Slow & 1 & 2 & -3 \\
Passive & -1 & 0 & -3 \\
\hline
\end{tabular}

Table 5. The results of the defined central tendency in the assessment of speaking according to the factor of emotional expressiveness.

\begin{tabular}{cccc}
\hline $\begin{array}{c}\text { Psycho-acoustic } \\
\text { qualities of the voice }\end{array}$ & $\begin{array}{c}\text { Personal mark } \\
\mathrm{M}_{\mathrm{e}}\end{array}$ & $\begin{array}{c}\text { Expert mark } \\
\mathrm{M}_{\mathrm{e}}\end{array}$ & $\begin{array}{c}\text { Desired mark by } \\
\text { the surveyed } \mathrm{M}_{\mathrm{e}}\end{array}$ \\
\hline Quiet & 0 & 2 & 3 \\
Monotonous & -2 & -2 & -3 \\
Restrained & 1 & -1 & 3 \\
Loud & 1 & 1 & 3 \\
\hline
\end{tabular}

Table 6. The results of the defined central tendency in the assessment of speaking according to the factor of intelligence.

\begin{tabular}{cccc}
\hline $\begin{array}{c}\text { Psycho-acoustic } \\
\text { qualities of the voice }\end{array}$ & $\begin{array}{c}\text { Personal mark } \\
\mathrm{M}_{\mathrm{e}}\end{array}$ & $\begin{array}{c}\text { Expert mark } \\
\mathrm{M}_{\mathrm{e}}\end{array}$ & $\begin{array}{c}\text { Desired mark by } \\
\text { the surveyed } \mathrm{M}_{\mathrm{e}}\end{array}$ \\
\hline Vulgar & -2 & -1 & -3 \\
Cheerful & 2 & 2 & 3 \\
Intelligent & 1 & 0 & 3 \\
Serious & 1 & 2 & 3 \\
Replete & 2 & 1 & 3 \\
Clear & 2 & 1 & 3 \\
\hline
\end{tabular}

The results of the study of various properties of speech using the method of semantic differential and found central tendencies allowed to consider the evaluation of the properties of speech of the surveyed generally adequate, except for the subjective assessment of emotional expression and a factor of intelligence.

In ideal profiles the three indicators (students', experts' and interested persons' marks) must be approximately equal. This indicates adequate self-esteem, social maturity and awareness.

The research of the speech with the method of semantic differential of future seafarers showed that:

- students are aware of the need to develop clear, assertive, loud speaking as a tool for communication and dialogue in the conditions of life at sea;

- students feel that the naturalness of speech is more appropriate;

- students' speech appeared to be adequate;

- emotional expression and the qualities related to the intelligence factor of the future seafarers' speech need correction. 


\section{Discussion}

We have been researching the foreign language acquisition by the students of the maritime educational establishments. But we must admit that analyzing quality of the speech students do not always separate their native and foreign languages speaking. Anyway, we think that the results can be considered valid despite the influence of the native language.

The other point for discussion concerns the method of semantic differential. The question is to what extend we can consider the points of view of teachers to be a subjective assessment of the surveyed speech. Besides, we doubt students' ability to analyze such wide range of the qualitative characteristics of their speech.

Generalizing, we speak about future seafarers' speech but we should admit that the results may be different depending on the country.

The results of diagnostics of the development of perceptive and speaking skills, the assessment of the quality of future seafarers' speech and the levels of development of skills and abilities of the listener prompted us to create psycholinguistic exercises to improve speech perceptual and productive skills. The exercises are based on the psychophysiological patterns of professional self-realization of personality (Kokun et al., 2015).

Bellow, we offer the examples of psychological games to make a correction of the perception of speech (Tyron, 2015).

1) Improvement of the personal profile of the auditor.

Exercise "Paraphrasing"

The aim of the exercise:

- to develop skills of reformulation of questions in the interaction with the interlocutor.

Course of the exercise: the participants are grouped into groups of $3-4 \mathrm{stu}-$ dents. The teacher gives a topic for discussion to work out the technique of paraphrasing. The one who listens first, always poses questions and then proceeds to reformulation. Then the participants switch roles. The teacher explains to the group: it happens that people perceive questions as an invasion into their personal space, as aggression, therefore it is better to use narrative form. This technique is to soften the question. For example, the phrase "Is it bothering you?" is possible to formulate "I think this situation might bother you" or "How do you feel when you hear such things?", or "These words may cause unpleasant feelings, am I right?" In addition, the technique of paraphrasing allows having a clear understanding about the subject of conversation when it is not clear, going to a deeper level of awareness of the problem.

Comments for the teacher: the teacher can prepare in advance and to provide the participants with the topics like "Profession of a sailor", "My favorite things", "The unpleasant situation that happened last week". At the same time, the participants themselves develop skills of communicative competence and nonaggressive behavior. 
2) Improving semantic personal speech profile

Exercise "Beaufort Scale"

The aim of the exercise:

- development of abilities to control the quality of speech;

- development of assertiveness of the voice.

Course of the exercise: the participants present the ability to change the loudness of voice that is necessary under different weather conditions on the Beaufort scale. First, students speak louder, then vice versa. Students work in pairs, one student tells the number of points on the Beaufort scale, the other gives the command.

Comments for the teacher: discuss if it was easy to "switch" the volume of the voice, is it easy to control the sound of the voice.

\section{Conclusions}

Requirements to the psycho-acoustic properties of the voice of future seafarers are caused by the conditions of their life and their future duties. Noise, vibration, bad weather require skills to wield the power of voice (psycho-acoustic dimensions). The need to speak in such conditions requires the ability to control the sound when speaking. Based on the fact that the students of higher educational institutions of marine areas-the future officers, their speech should be clear and assertive. Psycho-acoustical aspect, in our opinion, precedes the development of speech perception skills and the ability to control the sound of speech.

With the help of the method "Individual profile of an auditor", the following drawbacks in the perception formation as a determinant of communication skills of the future seafarers have been found:

- lack of attention and concernment in the perception of speech;

- lack of concentration during the hearing;

- the students have not thought of how they display their "ego" in communication.

The development of skills connected with these drawbacks requires improvement in the process of seafarers training.

The research of the speech with the method of semantic differential of future seafarers showed that:

- students are aware of the need to develop clear, assertive, loud speaking as a tool for communication and dialogue in the conditions of life at sea;

- students feel that the naturalness of speech is more appropriate;

- students' speech appeared to be adequate.

- emotional expression and the qualities related to the intelligence factor of the future seafarers' speech need correction.

Mapping the requirements to quality characteristics of the speech of future seafarers in the process of life activity on the ship and the results of the study of qualitative characteristics of the speech of the surveyed gave the reason to consider it advisable to use in the classroom exercises on the improvement and correction of individual qualitative characteristics of speech when teaching a foreign 
language-especially those exercises related to speech perception (emotional and intellectual spheres of speech).

\section{Highlights}

- psycholinguistic aspect of acoustic characteristics of the voice perception and speech production can be studied empirically;

- formation of foreign language competence includes the understanding of internal mechanism of perception of information by an individual;

- psycholinguistic exercises can improve speech perceptual skills of future seafarers;

- perceptial skills and abilities enable professionals to implement them effectively in professional and interpersonal communication.

\section{Acknowledgements}

The author would like to acknowledge Professors Kokun O., Maksimenko S. from the G. S. Kostiuk Institute of Psychology of NAPS of Ukraine for the support of her ideas in the research of future seafarers' foreign language competence.

\section{References}

Baskakova, I., \& Glukhov, V. (2009). Workshop on Psycholinguistics: Study Guide. Moscow: Astrel.

Cole, R. A., \& Scott, B. (1974). Towards a Theory of Speech Perception. Psychological Review, 81, 348-374. https://doi.org/10.1037/h0036656

Cleason, J. B., \& Ratner, N. B. (1998). Psycholinguistics. Orlando, Fl: Harcourt College Publishers.

Kalmykova, L. (2005). Psycholinguistics in the Teaching of Adults. Pedagogical Process: Theory and Practice. Journal of Scientific Works, 3, 120-123.

Leontiev, A. M. (1974). General Notion of Activity. Moscow: Nauka.

Leontiev, A. A. (1999). Fundamentals of Psycholinguistics. Moscow: Smysl.

Liberman, A. M., \& Mattingly, I. G. (1985). The Motor Theory of Speech Perception Revised. Cognition, 21, 1-36. https://doi.org/10.1016/0010-0277(85)90021-6

Liberman, P. (1965). On the Acoustic Basis of the Perception of Intonation by Linguist. Word, 21, 40-54. https://doi.org/10.1080/00437956.1965.11435417

Luria, A. (1975) Speech and Thinking. Moscow: Moscow State University Publisher.

MacKay, D. G. (1987). The Organization of Perception and Action: A Theory for Language and Other Cognitive Skills. New York: Springer. https://doi.org/10.1007/978-1-4612-4754-8

Miller, G. A., \& Iard, S. (1963). Some Perceptual Consequences of Linguistic Rules. Journal of Verbal Learning and Verbal Behavior, 2, 217-228. https://doi.org/10.1016/S0022-5371(63)80087-0

Osgood, C. (1967). Semantic Differential Technique in the Comparative Study of Cultures. In L. Jakobovits, \& M. S. Miron (Eds.), Readings in the Psychology of Language (pp. 371-397). New Jersey: Englewood Cliffs Prentice Hall.

Kokun, O. M., Klimenko, O. O., Korniaka, O. M., Malkhazov, O. R. et al. (2015) Psycho- 
physiological Patterns of Professional Self-Realization of Personality. Kyiv.: Pedagogical Thought.

Rubinstein, S. (1976) Problems of General Psychology. Moscow: Pedagogica.

Studdert-Kennedy, M. (1974). The Perception of Speech. In T.A. Sebeok (Ed.), Current Trends in Linguistics (Vol. 12, pp. 2349-2385). The Hague: Mouton.

Tarnopolskyi, O. B. (2006). Methods of Teaching Foreign Speaking Activity in a Higher Language Institution. Kiev: INKOS.

Tyron, O. (2015). Psychological Aspects of Teaching English for Students of Direction of Training "Sea and River Transport". In Tyron (Ed.), Psychotechnical Exercises and Psychological Games: Guidelines (85 p). Kiev: Reactiv-Print.

Ventsov, A., \& Kasevich, V. (2003). Problems of Speech Perception. Moscow: Editirial URSS Publisher.

Zasekina, L., \& Zasekin, S. (2002). Introduction to Psycholinguistics. Ostrog: Ostrog Academy Publisher.

Zimniaya, I. A. (1991). Psychology of Foreign Language Teaching. Moscow: Prosveshchenie.

Zhinkin, N. (1958). Mechanisms of Speech. Moscow: Academy of pedagogical sciences of RSFSR.

Submit or recommend next manuscript to SCIRP and we will provide best service for you:

Accepting pre-submission inquiries through Email, Facebook, LinkedIn, Twitter, etc. A wide selection of journals (inclusive of 9 subjects, more than 200 journals)

Providing 24-hour high-quality service

User-friendly online submission system

Fair and swift peer-review system

Efficient typesetting and proofreading procedure

Display of the result of downloads and visits, as well as the number of cited articles

Maximum dissemination of your research work

Submit your manuscript at: http://papersubmission.scirp.org/

Or contact psych@scirp.org 